'Wainwright RJ, Edwards AC, Maisey MN, Sowton E. Early occlusion and late stricture of normal coronary arteries following blunt chest trauma. Chest $1980 ; 78: 796-8$.

${ }^{8}$ Allen RP, Liedtke AJ. The role of coronary artery injury and perfusion in the development of cardiac contusion secondary to nonpenetrating chest trauma. F Trauma 1979;19:153-6.

${ }^{9}$ Rashid A, Chandraratna PA, Hildner FJ, Samet P, Yahr WZ, Greenberg J. Papillary muscle rupture following nonpenetrating chest trauma: report of a case with hemodynamic and serial echocardiographic findings and successful surgical treatment. Heart Lung 1978;7:647-51.

10 Patton AS, Guyton SW, Lawson DW, Shannon JM. Treatment of severe atrial injuries. Am $\mathcal{F}$ Surg 1981;141:465-71.

"Hendel PN, Grant AF. Blunt traumatic rupture of the heart. Successful repair of simultaneous rupture of the right atrium and left ventricle. 7 Thorac Cardiovasc Surg 1981 ;81:574-6.

${ }^{12}$ Michelson WB. CPK-MB isoenzyme determinations: diagnostic and prognostic value in evaluation of blunt chest trauma. Ann Emerg Med 1980;9:562-7.

${ }^{13}$ Green ED, Simson LR Jr, Kellerman HH, Horowitz RN, Sturner WQ Cardiac concussion following softball blow to the chest. Ann Emerg Med $1980 ; 9: 155-7$

${ }^{14}$ Reynolds $M$, Jones JW. CPK-MB isoenzyme determinations in blunt chest trauma. $\mathcal{F} A C E P$ 1979;8:304-6.

15 Schick TD, Van Der Zee H, Powers SR. Detection of cardiac disturbances following thoracic trauma with high-frequency analysis of the electrocardiogram. F Trauma 1977;17:419-24.

\section{Parathyroid hypertension}

Since the advent of multichannel autoanalysers the number of patients diagnosed as having primary hyperparathyroidism has risen sharply. Hunter Heath et al ${ }^{1}$ reported a fourfold increase in the diagnosis after measurements of serum calcium concentrations became routine. The clinical range has dramatically shifted from the classical description of "bones, stones, and abdominal groans" to that of the asymptomatic patient discovered by routine biochemical analysis of the blood.

Hypertension is common in hyperparathyroidism but for some reason this association is not well recognised. It was first studied systematically by Hellström et $a l^{2}$ in 1958. Since then various authors ${ }^{3}$ have reported hypertension to be present in between $10 \%$ and $60 \%$ of patients with primary hyperparathyroidism. The wide variation in these figures may be due to different criteria for selection of patients and defining hypertension.

At present the mechanism of parathyroid hypertension is not clear. The two conditions appear together too frequently to be due to a chance association. Avioli ${ }^{4}$ has suggested that hyperparathyroidism is 10 times more frequent in patients with otherwise "essential" hypertension than in the general population. Conversely, another recent case-control series ${ }^{1}$ reported a higher chance of hypertension in patients with primary hyperparathyroidism. The known links between hyperparathyroidism and other endocrinopathies, including phaeochromocytoma, Cushing's syndrome, Conn's syndrome, and acromegaly, are too rare to be blamed for the hypertension. So can the association be explained?

The hypercalcaemia of hyperparathyroidism is known to cause renal damage, and this might be blamed for the raised blood pressure. Hellström and colleagues ${ }^{2}$ reported a good correlation between the severity of renal impairment and the presence of hypertension. Some authors ${ }^{25}$ have suggested that preoperative renal function might be an important determinant of the response of the blood pressure to parathyroidectomy. Other studies, ${ }^{6} 7$ however, have shown that hypertension does not correlate closely with renal damage and that renal function and blood pressure do not improve after surgery and may even become worse-or impairment may develop for the first time. The part played $\stackrel{\text { W }}{z}$ by the renin-angiotensin system in the pathogenesis of parathyroid hypertension is equally controversial. Brinton and $c$ colleagues ${ }^{8}$ found raised plasma renin activity in four patients $\widehat{\Omega}$ with hyperparathyroidism and hypertension. Serum calcium $\bar{\Xi}$ concentrations and the plasma renin activity returned to normal in all four patients after surgery; the blood pressure क also returned to normal in three and decreased considerably $\stackrel{\text { }}{\varrho}$ in the fourth. On the other hand, Zawada and colleagues ${ }^{9} \stackrel{-}{=}$ claim that hypertension associated with hyperparathyroidism $\stackrel{5}{\rightarrow}$ is not dependent on renin. They showed that infusion of the competitive angiotensin antagonist saralasin failed to lower $\frac{\bar{\sigma}}{\bar{N}}$ the blood pressure in all of their five patients including three $\frac{\vec{\sigma}}{\sigma}$ with high plasma renin activity.

Calcium plays an essential part in the excitation and $\%$ contraction of both striated and smooth-muscle cells. ${ }^{10}$ Studies $\vec{O}$ in both animals and $\operatorname{man}^{11} 12$ have shown that intravenous $\overrightarrow{\vec{H}}$ infusion of calcium has a peripheral vasoconstrictor effect, $\stackrel{\omega}{\sigma}$ and increased peripheral resistance may play a part in the $\frac{}{3}$ hypertension associated with primary hyperparathyroidism. i Experimental evidence ${ }^{13}$ also shows that the release of $\infty$ catecholamines is calcium dependent. Higher concentrations $\dot{\omega}$ of catecholamines and their metabolites have been reported in patients with primary hyperparathyroidism together with increased vascular reactivity to noradrenaline infusions. This $\infty$

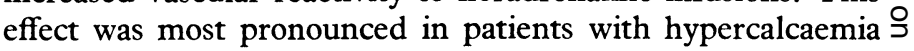
who also had hypertension. Enhanced sympathetic activity $\vec{N}$ might therefore account for the raised blood pressure in $T$ hypercalcaemic patients. The inconsistencies in reports of the $\frac{\mathbb{O}}{2}$ effects of parathyroid surgery on the blood pressure, despite the drop in serum calcium concentrations, suggest that the calcium itself is unlikely to be a pressor agent.

Raised concentrations of parathyroid hormone cannot be blamed for the hypertension, as administration of the hormone and its end terminal 1-34 fragment is associated with a fall in blood pressure. ${ }^{14}$ Again, a fall in hormone concentrations after surgery does not correspond to a fall in blood pressure. $\frac{\&}{\varnothing}$

An interesting hypothesis implicating skeletal sodium suggests that in hyperparathyroidism sodium is liberated from skeletal stores, so raising the blood pressure in susceptible subjects. ${ }^{15}$ Possibly this sodium mechanism may complement the sympathetic activity.

Though hypertension is undoubtedly common in hyperparathyroidism, this does not explain the association of $\frac{0}{-}$ hypercalcaemia with high blood pressure in epidemiological studies. Bulpitt et $a l^{16}$ found a positive correlation between $\delta$ the serum calcium concentration and systolic blood pressure in the Whitehall study. A link between blood pressure and 9 calcium is further supported by Kesteloot and Geboers, ${ }^{17} \mathrm{~N}$ whose epidemiological study of Belgian soldiers showed an independent and highly positive correlation between serum calcium concentrations and both systolic and diastolic $N$ pressure. In this case, however, they could be sure that the relation was not influenced by the use of thiazide diuretics in hypertensive patients, but a study in Renfrew, Scotland, ${ }^{18} 0$ has supported the relation between calcium and blood pressure $\Phi$ in a population not using thiazide diuretics. This association $\stackrel{?}{?}$ between serum calcium concentrations and blood pressure in the population is particularly surprising as blood pressures are $\frac{\vec{D}}{\Phi}$ generally lower in populations resident in areas supplied with $\frac{O}{\mathbb{D}}$ drinking water with high calcium content. ${ }^{19}$

The links between the parathyroids and hypertension and the part played by calcium in the pathogenesis of essential $\frac{8}{0}$ hypertension seem likely to receive more attention in the next few years. More information is needed on the place of surgery 
in symptomless hypertensive patients with hyperparathyroidism. The meaning of the epidemiological association of calcium and blood pressure also needs elucidating.

\section{A K SANGAL}

Research fellow

D G BEEvers

Dudley Road Hospital,

Senior lecturer in medicine

Birmingham B18 7QH

' Heath H, Hodgson SF, Kennedy MA. Primary hyperparathyroidism: incidence, morbidity and potential economic impact in a community. $N$ Engl f Med 1980;302:189-93.

'Hellström J, Birke G, Edvall CA. Hypertension in hyperparathyroidism. Br F Urol 1958;30:13-24.

${ }^{3}$ Christensson T, Hellström K, Wengle B. Blood pressure in subjects with hypercalcaemia and primary hyperparathyroidism detected in health screening programme. Eur f Clin Invest 1977;7:109-13.

+ Avioli LV. Stones, bones, abdominal groans, psychic moans and hypertones. Cardiovascular Medicine 1978;3:835-9.

"Ohlsson L. Renal function in hyperparathyroidism. A follow-up study three to nine years after surgery comprising 35 cases. Acta Endocrinol (Copenh) 1970;63:171-4.

${ }^{6}$ Britton DC, Thompson MH, Johnston IDA, Fleming LB. Renal function following parathyroid surgery in primary hyperthyroidism. Lancet $1971 ;$ ii :74-5.

'Rosenthal FD, Roy S. Hypertension and hyperparathyroidism. Br Med $\mathcal{F}$ 1972 ;iv:396-7.

* Brinton GS, William J, Lagerquist LD. Hypertension in primary hyperparathyroidism: the role of the renin-angiotensin system. $\mathcal{F}$ Clin Endocrinol Metab 1975;41:1025-9.

9 Zawada ET Jr, Brickman AS, Maxwell MH, Tuck M. Hypertension associated with hyperparathyroidism is not responsive to angiotensin blockade. 7 Clin Endocrinol Metab 1980;50:912-5.

1" Seidel CL, Bohr DF. Calcium and vascular smooth muscle contraction. Circ Res $1971 ; 28$ and 29, suppl 2:88-95.

11 Frohlich ED, Scott JB, Haddy FJ. Effect of cations on resistance and responsiveness of renal and forelimb vascular beds. Am $\mathcal{F}$ Physiol $1962 ; 203: 583-7$

1: Weidmann P, Massry SG, Coburn JW, Maxwell MH, Atleson J, Kleeman CR. Blood pressure effects of acute hypercalcemia. Studies in patients with chronic renal failure. Ann Intern Med 1972;76:741-5.

13 Vlachakis ND, Frederics $R$, Velasquez $M$, Alexander $N$, Singer $F$, Maronde RF. Sympathetic system function and vascular reactivity in hypercalcemic patients. Hypertension $1982 ; 4: 452-8$

14 Pang PKT, Yang MCM, Tenner TE, Chang JK, Shimizu M. Hypotensive action of synthetic fragments of parathyroid hormone. 7 Pharmacol Exp Ther $1981 ; 216: 567-71$.

${ }^{15}$ Michell AR. Skeletal sodium: a missing element in hypertension and salt excretion. Perspect Biol Med 1976;20:37-43.

${ }^{16}$ Bulpitt CJ, Hodes C, Everitt MG. The relationship between blood pressure and biochemical risk factors in a general population. British Fournal of Preventive and Social Medicine 1976;30:158-62.

17 Kesteloot H, Geboers J. Calcium and blood pressure. Lancet $1982 ; \mathrm{i}: 813-5$.

18 Sangal AK, Beevers DG. Serum calcium and blood pressure. Lancet $1982 ;$ ii : 493 .

19 Stitt FW, Clayton DG, Crawford MD, Morris JN. Clinical and biochemical indicators of cardiovascular disease among men living in hard and soft water areas. Lancet $1973 ; \mathrm{i}: 122-6$.

\section{Pneumocystis pneumonia}

Pneumocystis pneumonia was originally described in the 1940 s as an epidemic disease affecting premature or malnourished infants in eastern Europe. In Britain Pneumocystis carinii has been recognised since 1955 as the cause of an interstitial pneumonia carrying a high mortality, ${ }^{1}$ but its behaviour is still a puzzle. Probably a sporozoan, it alternates between trophic and cystic phases and can multiply rapidly with an asexual life cycle. ${ }^{2}$ Serological data suggest that carriage of the organism is extremely frequent in early life, ${ }^{3}$ giving rise to the concept (as yet unproved) that the pneumonia may sometimes develop as an opportunistic infection resulting from reactivation of latent organisms in immunosuppressed individuals.
Until 1981 the disease was most commonly seen in patients receiving cytotoxic treatment for leukaemia and lymphoma. ${ }^{4}$ In the past 12 months, however, the aptly named "gay compromise syndrome" has brought the problems of diagnosis and management of pneumocystis pneumonia to a wider audience. ${ }^{5}$ The syndrome occurs chiefly in healthy homosexual men ${ }^{6}$ but also in women ${ }^{7}$ and may include a range of opportunistic infections, particularly pneumocystis pneumonia, and also Kaposi's sarcoma. The pneumonia in such patients may be rapidly progressive with a mortality of $40 \%$ despite treatment.

The syndrome has been recognised mainly in North America, where the incidence is rising sharply, but cases have also been described in Britain and in Denmark. ${ }^{8}{ }^{9}$ Its basis appears to be acquired immunosuppression, possible causes of which include cytomegalovirus infection and the liberal use of "recreational" drugs such as inhaled nitrites, both of which are common among homosexuals. Certainly the syndrome provides one of the clearest instances of the profound effects of immunosuppression, and further research by virologists, immunologists, and tumour biologists may well prove fruitful on several fronts.

What are the problems of diagnosis of pneumocystis pneumonia and how is it treated ? The pneumonia presents clinically with severe dyspnoea, often acute in onset, together with a nonproductive cough, fever, and loss of weight. Physical signs in the chest are characteristically few, despite both the degree of dyspnoea and the radiographic picture, which typically shows diffuse bilateral shadowing giving a ground glass appearance. Serological tests are of little diagnostic value, and efforts to culture the organism have met with only very limited success. ${ }^{10}$ Hence the diagnosis is generally made by microscopical examination of tissue obtained either by open lung biopsy or else by less invasive measures such as percutaneous needle, transbronchial, or endobronchial brush biopsy.

Untreated, pneumocystis pneumonia carries a mortality of virtually $100 \%$ and, despite some recent progress, patients may still die-not least because of other serious opportunistic infections in immunosuppressed individuals. Pentamidine isethionate ( $4 \mathrm{mg} / \mathrm{kg} /$ day) has been shown to be effective treatment for pneumocystis pneumonia in all age groups, but the drug has toxic effects on the kidneys and the liver and gives serious local reactions in up to half of patients treated. ${ }^{4}$ In 1975 Hughes and colleagues showed that co-trimoxazole was also effective in children in doses greater than those usually used for bacterial infections. ${ }^{11}$ In a randomised trial cotrimoxazole was as effective as pentamidine (recovery rates of $77 \%$ and $75 \%$ ), but was clearly much less toxic. ${ }^{12}$ More recently Sattler and Remington have confirmed that at the appropriate dose co-trimoxazole is highly effective given by the intravenous route in seriously ill adults as well as in children suffering from pneumocystis pneumonia, with $80 \%$ of patients responding to treatment. ${ }^{13}$ Finally, Hughes et al ${ }^{14}$ showed in a placebo controlled randomised trial that prophylactic use of cotrimoxazole reduced the incidence of pneumocystis pneumonia among children receiving treatment for acute leukaemia, and this policy has attracted increasing popularity. More recently, however, Hughes has added a note of caution with evidence from studies on immunosuppressed rats that co-trimoxazole could not eradicate $P$ carinii from the lungs, and he concluded that patients might be protected only during the period of drug administration. ${ }^{15}$

S B KAYE

Senior Lecturer in Clinical Oncology,

University of Glissgow,

Glasgow G12 9LY 